\title{
Possibilidades de uso direto de altitude elipsoidal em obras de engenharia
}

\author{
Daniel Carneiro da SILVA \& Claudia Vergetti de A. SILVA
}

\begin{abstract}
Programa de Pós Graduação em Ciências Geodésicas e Tecnologias da Geoinformação, Universidade Federal de Pernambuco. Av. Professor Morais Rego, 1235 - Cidade Universitária, 50670-901, Recife, PE, Brasil. (daniel.csilva@ufpe.br, claudia_vergeti@hotmail.com).
\end{abstract}

Recebido em 10/2015. Aceito para publicação em 07/2017.

Versão online publicada em 21/10/2017 (www.pesquisasemgeociencias.ufrgs.br)

\begin{abstract}
Resumo - As alturas e diferenças de altura nas obras de engenharia são determinadas normalmente por nivelamento topográfico geométrico, que fornece as altitudes ortométricas, mas também está sendo usado o nivelamento com receptores GNSS (Global Navigation Satellite System) que fornece altitudes elipsoidais. As primeiras são medidas em relação ao geoide, mas também podem ser obtidas a partir das altitudes elipsoidais, desde que seja conhecida a ondulação geoidal no local. Como essa transformação contém erros inerentes aos nivelamentos e métodos de obtenção da ondulação geoidal, essa metodologia não tem fácil aplicação na prática diária das engenharias. Este trabalho tem por objetivo analisar as possibilidades de uso da altitude elipsoidal em obras de engenharia de modo direto, sem a sua transformação para a altitude ortométrica. Para isto foram executados inicialmente nivelamentos geométricos e GNSS em uma área com 2,13 km², de modo a gerar um mapa de ondulação geoidal local de acordo com a metodologia usual de transformação. Neste processo foi possível identificar vários erros grosseiros de diversas origens no nivelamento GNSS; comparar as precisões das altitudes pelos dois métodos e analisar a influência dos erros na geração do geoide e na grandeza dos gradientes de suas ondulações.Na verificação do uso direto do nivelamento GNSS em obras de declividade muito baixa que exigem grande precisão de nivelamento geométrico,é proposta uma análise conjunta dos valores dos gradientes e dos sentidos das declividades da obra e da ondulação geoidal. Finalmente, são sugeridos procedimentos a serem seguidos sobre o uso direto de altitudes elipsoidais, de acordo com as especificações de nivelamentos de baixa, média e alta precisão em obras de engenharia civil.
\end{abstract}

Palavras-chave: altitude ortométrica, altitude geométrica, ondulação geoidal.

Abstract - PossibiLITIES OF DIRECT USE OF ELLIPSOIDAL ELEVATION IN ENGINEERING WORKS. The heights and height differences in engineering works are usually determined by differential levelling, which provides orthometric altitudes. However the levelling with GNSS (Global Naviation Satellite System) receivers, which provides ellipsoidal altitudes, is also being disseminated. The former are measured in relation to the geoid surface and may also be obtained through ellipsoidal altitudes, as long as the geoid undulation in the place is known. Since this transformation contains errors inherent to the levelling and methods used for obtaining the geoid undulation, this methodology is not easily applicable in the daily practice of engineering. This work aims to analyse the possibilities of the use of ellipsoidal altitudes in engineering works directly, without the transformation to orthometric altitude. For this, topographic and GNSS levelling were made in an area with $2,13 \mathrm{~km}^{2}$ to generate a local geoid undulation map according to the usual ransformation methodology. In this process, several large mistakes of diverse origins were found. Also, the precision of the altitudes acquired by the GNSS and geometric levelling methods, as well as the influence of the errors in the generation of the geoid and its undulation gradients were compared and analised.. In the verification of the direct use of GNSS levelling in works of the very low declivity, such as drainage canals, which require great precision, an analysis of the gradients values and declivities direction is proposed.. Finally, they are suggested procedures to be followed by the direct use of ellipsoidal altitudes, according to the specifications for civil engineering works that require levelling of low, medium and high precisions.

Keywords: orthometric height, geometric elevation, geoid undulation. 


\section{Introdução}

De modo geral as obras de engenharia necessitam de medições de alturas e de desníveis do terreno e elementos do projeto, com diferentes intervalos ou graus de precisões, de alguns milímetros a vários centímetros, em valores absolutos ou relativos e nas diferenças nos casos de cálculos de declividades. Já em mapeamentos topográficos, as diferenças de altitude ou de altura do terreno variam de centímetros a metros, conforme a finalidade e escala do mapa.

Nas ciências geodésicas existem vários tipos de altitudes, sendo mais conhecidas as altitudes ortométricas e as geométricas (ou elipsoidais). As altitudes ortométricas são determinadas através de nivelamentos geométricos e de correções ortométricas obtidas de informações gravimétricas, sendo as mais indicadas para as engenharias porque definem o sentido de escoamento de líquidos e a verticalidade de prédios. Já as altitudes elipsoidais são obtidas através dos receptores GNSS (Global Navigation Satellite System), e são de grandeza puramente matemática, pois se referem ao Elipsoide adotado para o sistema geodésico de referência. Os receptores GNSS vêm sendo atualmente utilizados também para levantamentos topográficos por serem instrumentos de fácil utilização no campo e de rápida obtenção de coordenadas, inclusive para nivelamentos em aplicações de menor precisão.

Para evitar possível confusão de terminologia, neste artigo, o nivelamento topográfico geométrico é o que obtém as altitudes ortométricas (embora não sejam realizadas as correções gravimétricas), a altitude geométrica derivada do GNSS será chamada de altitude elipsoidal e o levantamento de altitudes com GNSS de nivelamento GNSS.

A altitude elipsoidal pode ser transformada em altitude ortométrica desde que se conheça a ondulação geoidal do lugar. Para isto o IBGE (Instituto Brasileiro de Geografia e Estatística) disponibiliza o MAPGE02015 (Modelo de Ondulação Geoidal) para o Brasil, com uma resolução de 5' de arco. 0 sistema de interpolação fornece a ondulação geoidal (N) nos pontos desejados, referida aos sistemas geodésicos de referência SIRGAS2000 (Sistema de Referência Geocêntrico para as Américas, em sua realização do ano de 2000) e SAD69 (South American Datum 1969). No Brasil, o desvio padrão da ondulação do MAPGE02015 é de 17 $\mathrm{cm}$, sendo que em alguns países, como nos E.U.A. (NOAA, 2008), a precisão chega a poucos centímetros (Seeba, 2003).

Autores como Svábensky \& Weigel (2002) e Seeber (2003) relacionam as aplicações de levan- tamentos GNSS em vários serviços e obras de engenharia, sendo que o último ainda mostra que as altitudes GNSS podem ser usadas diretamente para monitorar deslocamentos verticais. De modo geral a conversão de altitude elipsoidal para altitude ortométrica para uso em obras e serviços de engenharia obedecem alguns procedimentos padrões a partir de um geoide local obtido por medições com GNSS, como visto em alguns trabalhos acadêmicos realizados no Brasil, como Arana $(2003,2004)$, Goldani \& Quintas (2010) e Cerqueira \& Romão (2010). Porém o uso direto da altitude GNSS, sem a conversão para ortométrica, nas aplicações gerais em engenharia é raramente discutido, sendo exceções El-Shazly \& Adel (2005) e Silva (2012).

As exigências de precisão da altimetria das obras de engenharia podem ser enquadradas nos mesmos padrões das normas do nivelamento geométrico em baixa, média e alta precisão, sendo que as determinações de geoides têm precisões suficientes para baixa e média precisão (Seeber, 2003). Ocorre ainda que sob as condições de serviços na prática diária da engenharia a obtenção de um geoide local e preciso não é tarefa trivial, e nem sempre é adotada a metodologia adequada. As determinações de geoides de precisão no Brasil ainda enfrentam dificuldades. Segundo Monico (2000) é um objetivo ainda a ser alcançado e segundo (Souza \& Sá, 2007) esse problema pode ter origem em distorções da rede ortométricas. Em Zilkoski et al. (1997) é discutida a necessidade da observação rigorosa de várias ações a serem executadas para a obtenção de geoides de alta precisão, na ordem de 2 a $5 \mathrm{~cm}$, nos EUA (NOAA, 2008), sendo necessário para isso cumprir especificações que envolvem três regras básicas, quatro sugestões de controle e cinco procedimentos, todos eles muito bem definidos.

Este trabalho analisa inicialmente os principais fatores que afetam a precisão durante a obtenção de um geoide local, com ênfase no método geométrico, mais usado na prática, e propõe uma análise das declividades em obras de drenagem comas relações entre as declividades mínimas e máximas das ondulações geoidais. Propõe também um indicador de precisão para o nivelamento GNSS que facilite a comparação com os padrões dos nivelamentos geométricos adotados em obras e projetos. Em seguida são analisados os resultados dos diversos nivelamentos GNSS realizados para gerar um geoide local suficientemente preciso, em uma área com alguns quilômetros quadrados, cujas dimensões são compatíveis, por exemplo, com obras de urbanização e drenagem. As discrepâncias de altitudes encontradas entre várias determinações 
em pontos da rede, incluindo resultados dos processamentos com programas diferentes e medições repetidas, são discutidas e comparadas com os padrões técnicos de nivelamento geométrico e com exemplos de exigências mais rigorosas em obras de drenagem. Essas análises permitiram definir sugestões de procedimentos para uso direto das altitudes elipsoidais, sem a usual transformação para ortométrica, para obras com níveis de precisões baixo e médio.

\section{Materiais e métodos}

Para os experimentos foi escolhida uma área com cerca $2,0 \mathrm{~km}^{2}$ e maior linha de base com cerca de 1,4 km, dimensões consideradas adequadas, por exemplo, para projetos de engenharia como urbanização de ruas ou implantação de obras de drenagem.

A definição da metodologia partiu de duas considerações principais. A primeira utiliza bases da teoria presente em ampla literatura e dos usos na prática corrente em ambientes de execução de obras, que envolvem os nivelamentos GNSS e conversões para altitudes ortométricas com um geoide geométrico local. A segunda analisa as características e diferenças entre os tipos de nivelamentos quanto aos indicadores de precisão, as relações entre as declividades do geoide e projeto e suas implicações nas obras de engenharia, visando o uso direto do nivelamento GNSS e como os erros deste podem interferir em obras de drenagem.

Para cumprir esse objetivo foram observadas algumas premissas definidas a seguir .

0 procedimento padrão para conversão de altitudes elipsoidais para ortométricas é usar um geoide, obtido por algum método que forneça a precisão necessária, de modo que se obtenha a ondulação geoidal no ponto desejado. Porém, no dia a dia são implantados os geoides geométricos com metodologias não adequadas, simples, rápidas e sem controles estatísticos que podem não atingir a precisão necessária (Monico, 2000). Para fins de avaliação desse procedimento foi gerado um geoide com método simples, porém com adequado controle de precisão.

Os critérios de avaliação de precisões dos nivelamentos, geométrico e GNSS, são diferentes, sendo necessário definir um modo fácil de comparação. Enquanto no nivelamento geométrico a precisão é avaliada por um valor de tolerância máxima proporcional à distância entre os pontos extremos de cada trecho nivelado, em seções ou no total, no GNSS a precisão é informada pelo relatório de processamento e tem relação com a distância à base e não entre pontos sucessivos.

Os levantamentos GNSS têm precisão muito menor que o indicado pelos relatórios de processamento (Monico, 2000) e também as altitudes têm precisão menor que as planimétricas (Seeber, 2003; Stepniak et al., 2013). Além disso, tem sido observadas diferenças significativas de coordenadas planimétricas e altimétricas nas comparações de processamentos com softwares diferentes, rastreio em horários e dias diferentes, e entre os métodos de rastreio. Estas discrepâncias têm implicações nas altitudes obtidas diretamente ou transformadas.

A ondulação do geoide varia poucos milímetros em pequenas áreas, portanto não apresenta picos ou depressões. Isto implica que pode ser estimado o erro sistemático ao se usar o nivelamento GNSS diretamente a partir de um modelo de ondulação nacional existente, como o MAPGEO, e serem analisadas as tolerâncias nas altitudes de obras desde poucos metros de extensão até vários quilômetros, como em estradas ou canais.

\subsection{Considerações quanto às precisões de nivela- mentos e tipos de geoides}

As precisões e tolerâncias nas altitudes necessárias para os projetos e obras de engenharia variam de milímetros a metros, e exigem métodos de levantamentos adequados conforme o grau de projeto preliminar (projeto básico ou anteprojeto), projeto definitivo (ou executivo) ou controle e execução da obra, e ainda conforme o grau de precisão baixo, médio ou alto. Os padrões mais baixos podem ser atendidos com nivelamento trigonométrico, taqueométrico e pelo GNSS, enquanto os médios e altos normalmente com o nivelamento geométrico, sendo que esses últimos são objetos de análise deste trabalho, para serem atendidos também pelo nivelamento GNSS. As questões que envolvem as precisões dos nivelamentos, modelos de geoides e relações com obras de engenharia serão discutidas nas seções a seguir.

\subsubsection{Precisões do nivelamento geométrico}

As precisões de nivelamento geométrico no Brasil são normalizadas pelo IBGE e pela norma NBR 13333 da ABNT (Associação Brasileira de Normas Técnicas) (ABNT, 1994) em classes que definem algumas aplicações e suas precisões respectivas. Um nivelamento é aceito se a discrepância máxima direta, entre medições repetidas no mesmo ponto, for menor ou igual que o valor obti- 
do pela equação 1 que define o limite da tolerância para a extensão nivelada. A terminação da tolerância pode ser feita com a execução de um contra nivelamento, quando se trata de linhas simples, ou no caso de redes, em comparação com a altitude ou cota de ponto já conhecido.

$$
\mathrm{Th}=\mathrm{a} \cdot \sqrt{\mathrm{k}} \quad \text { (Equação } 1)
$$

Em que: Th, é a tolerância em milímetros para o trecho em avaliação; a, valor da constante definido pela classe do nivelamento geométrico, em milímetros; k, é a extensão do trecho em quilômetros.

A tabela 1 mostra as especificações do IBGE com os valores da constante a para nivelamentos com as classificações: alta precisão, precisão e topográfico.

Segundo as instruções do IBGE, o nivelamento geométrico de Alta Precisão é indicado para estudos científicos e controle de obras de engenharia; os nivelamentos de Precisão e Topográfico para controle de obras; e o Topográfico para parcelamento de terrenos e pequenas obras.

As recomendações da NBR 13133 para nivelamento geométrico são dadas na tabela 2 .

A tabela 2 mostra as classes IN e IIN. A classe IN é indicada para implantação de rede de apoio altimétrico, com tolerância $12 \mathrm{~mm}$ x $\sqrt{\mathrm{k}}$. Já a classe IIN, que é a recomendada para uso corrente em obras, tem tolerância é de $20 \mathrm{~mm} \mathrm{x} \sqrt{\mathrm{k}}$, enquanto que pelo IBGE, também para obras, a tolerância é menor, de apenas $12 \mathrm{~mm} x \sqrt{\mathrm{k}}$. Os padrões de precisão de nivelamento das tabelas 1 e 2 expressam a discrepância máxima permitida, relacionada com a extensão nivelada, obtida da diferença entre o nivelamento e o contra nivelamento.

Neste artigo é considerado, para fins práticos e facilidade de análises, que a discrepância do nivelamento geométrico (diferença absoluta entre duas medições, cotas ou altitudes) é equivalente a três sigmas ou 100\% de confiabilidade e que um sigma equivale a $68 \%$.

Tabela 1. Precisões de nivelamento geométrico IBGE (Resolução PR n. 22/83).

Table 1. IBGE differential levelling precision (Resolução PR n. 22/83).

\begin{tabular}{lllc}
\hline Classificação & Alta Precisão & Precisão & Topográfico \\
\hline Aplicação & Rede Fundamental & Área Desenvolvida & Local \\
Erro Padrão Máximo & $2 \mathrm{~mm} \times \sqrt{\mathrm{k}}$ & $3 \mathrm{~mm} \times \sqrt{\mathrm{k}}$ & $6 \mathrm{~mm} \times \sqrt{\mathrm{k}}$ \\
Dif. máxima/seção & $3 \mathrm{~mm} \times \sqrt{\mathrm{k}}$ & $6 \mathrm{~mm} \times \sqrt{\mathrm{k}}$ & $12 \mathrm{~mm} \times \sqrt{\mathrm{k}}$ \\
Dif. máxima/ linha & $4 \mathrm{~mm} \times \sqrt{\mathrm{k}}$ & $6 \mathrm{~mm} \times \sqrt{\mathrm{k}}$ & $12 \mathrm{~mm} \times \sqrt{\mathrm{k}}$ \\
\hline
\end{tabular}

Tabela 2. Precisões de nivelamento geométrico pela NBR 13133.

Table 2. NBR 13133 Differential levelling precision.

\begin{tabular}{lll}
\hline \multicolumn{1}{c}{ Classe } & \multicolumn{1}{c}{ IN Geométrico } & \multicolumn{1}{c}{ IIN Geométrico } \\
\hline Equipamento Nível & Alta precisão $\leq \pm 3 \mathrm{~mm} / \mathrm{km}$ & Média precisão $\leq \pm 10 \mathrm{~mm} / \mathrm{km}$ \\
Tolerância fechamento & $12 \mathrm{~mm} \times \sqrt{\mathrm{k}}$ & $20 \mathrm{~mm} \times \sqrt{\mathrm{k}}$ \\
Aplicação & RN de apoio altimétrico & Altitudes em obras de engenharia \\
\hline
\end{tabular}

\subsubsection{Precisão de nivelamento GNSS}

As altitudes obtidas por GNSS geralmente tem precisão menor, cerca da metade das coordenadas planimétricas (Seeber, 2003). Os valores das altitudes são influenciados por diversos erros provenientes de: indefinição do centro de fase da antena; propagação dos sinais na troposfera; medição da altura da antena; atraso do sinal (atmosfera e hardware); diferenças de processamentos entre softwares, qualidade do hardware e multicaminho. 0 leitor interessado nas análises das diversas fontes desses erros, ordens de grandeza e formas de mitigação encontra mais detalhes em Seeber (2003) e Werlich et al. (2012).
Os levantamentos relativos estáticos que são realizados com tempo de rastreio longos (horas) e comprimentos de linha de base adequados podem atingir a precisão de milímetros, mas em situações do dia a dia nas obras, os levantamentos e resultados devem ser quase sempre rápidos. A tabela 3 relaciona alguns valores indicativos de precisão de nivelamento GNSS, segundo os métodos de rastreio rápidos, para um e três sigmas (ou um e três desvios padrões) baseado em Higgins (1999), para as distâncias de 1,5 e $10 \mathrm{~km}$.

Na tabela 3 o erro de $33 \mathrm{~mm}$ com três sigmas, estimado para a extensão de $1 \mathrm{~km}$, é maior que os $20 \mathrm{~mm}$ da tolerância para o nivelamento geométrico da classe IIN da ABNT $(20 \mathrm{~mm} . \sqrt{\mathrm{k}})$ para a mes- 
ma distância, o que indica que a altimetria obtida com GNSS, usando métodos rápidos de rastreio, tem precisão menor que o nivelamento geométrico comum. Além disso, as altitudes obtidas com GNSS podem conter erros inevitáveis que somente são possíveis de detectar com medições de checagem com dois ou três rastreios, principalmente nos métodos rápidos (Wolf \& Ghilani, 1997; Svábensk y \& Weigel, 2002; Seeber, 2003).

Tabela 3. Precisão altimétrica de GNSS em mm com métodos rápidos (Higgins, 1999). Table 3. GNSS elevation precision in $\mathrm{mm}$ with fast methods (Higgins, 1999).

\begin{tabular}{lllllllll}
\hline Modo & mm & +ppm & \multicolumn{2}{c}{ Erro em mm (1sigma) } & \multicolumn{2}{c}{ Erro em mm (3 sigmas) } \\
\hline & & & $1 \mathrm{~km}$ & $5 \mathrm{~km}$ & $10 \mathrm{~km}$ & $1 \mathrm{~km}$ & $5 \mathrm{~km}$ & $10 \mathrm{~km}$ \\
\hline Estático Rápido & 10 & 1 & 11 & 15 & 20 & 33 & 45 & 60 \\
Cinemático & 20 & 1 & 21 & 25 & 30 & 63 & 75 & 90 \\
RTK 1 Hz & 20 & 1 & 22 & 30 & 40 & 66 & 90 & 120 \\
RTK 5 Hz & 50 & 2 & 52 & 60 & 70 & 156 & 180 & 210 \\
\hline
\end{tabular}

\subsubsection{Indicador de tolerância para o nivelamento GNSS}

Os padrões de precisão de nivelamento em topografia expressam a discrepância máxima permitida, relacionada com a extensão nivelada e comparada com o contra nivelamento. No caso de GNSS, as altitudes e precisões são fornecidas pelo relatório de processamento e estão relacionadas com o comprimento da linha de base, e não entre as distâncias entre dois pontos medidos sucessivamente. Devido a essa característica, que difere do nivelamento geométrico, é proposta aqui uma forma de comparação, adaptando a equação 1 para o nivelamento GNSS considerando k como sendo o comprimento da linha entre a base e receptor móvel, dada pela equação 2 .

$$
\mathrm{a}_{\text {gnss }}=\mathrm{Th} / \sqrt{\mathrm{k}} \quad \text { (Equação 2) }
$$

O indicador $\mathrm{a}_{\text {gnss }}$ será útil para comparações de discrepâncias entre altitudes medidas em repetições ou processamentos, com os padrões do nivelamento geométrico.

\subsubsection{Obtenção do Geoide e Ondulação Geoidal}

A transformação aproximada adotada na prática das altitudes elipsoidal para ortométrica de um ponto sobre a superfície topográfica é dada pela equação 3:

$$
\mathrm{H}=\mathrm{h}-\mathrm{N}
$$

(Equação 3)

Em que $\mathrm{H}$ é a altitude ortométrica desejada, $\mathrm{h}$ é a altitude geométrica obtida do sistema GNSS e N a ondulação geoidal naquele ponto.

As ondulações geoidais e suas precisões são conhecidas a partir de processos de determinações de geoides, que segundo a extensão são classificados em globais, regionais ou locais. Quanto à aquisição os métodos são classificados em geométrico, astro-gravimétrico, satelital e gravimétrico (Zhan-Ji, 1998 ; Arana, 2003). No método geométrico há a combinação de nivelamento geométrico com nivelamento GNSS e podem ser gerados três tipos de geoides que dependem da forma de processamento (Zhan-J i, 1998): interpolação direta das altitudes ortométricas comparadas com as elipsoidais; uso do método remove-restaura, só com modelo geopotencial; e combinação de modelo geopotencial com correções do terreno.

0 primeiro tipo é o mais conhecido como simplesmente com geométrico e o mais empregado na prática diária das engenharias por ser o mais fácil de ser obtido. Os demais tipos exigem aparelhagem especial (muitos receptores GNSS, gravímetros, etc.), métodos complexos de aquisição e de processamento (modelos de geopotencial, modelos do terreno, ajustamento de redes, etc).

Para o terceiro tipo, adotado por Zhan-Ji (1998) e Santos (2009), é usada a equação 4:

$$
\mathrm{N}=\mathrm{N}_{\mathrm{GM}}+\mathrm{N}_{\mathrm{dg}}+\mathrm{N}_{\mathrm{r}} \quad \text { (Equação 4) }
$$

Em que: $\mathrm{N}_{\mathrm{GM}}$ é a componente de onda longa calculada do modelo de geopotencial; $\mathrm{N}_{\mathrm{dg}}$ é a componente de onda média calculada usando integral de Stokess da anomalia da gravidade; $\mathrm{N}_{\mathrm{r}}$ é a onda curta que dá correções do terreno obtidas de MDT (Modelo Digital do Terreno).

0 efeito da topografia do terreno na determinação de um geoide aparece no termo $\mathrm{N}_{\mathrm{r}}$ da equação 4. Esse efeito segundo Zhang et al. (2000) não atinge $50 \mathrm{~cm}$ para altitudes de $3000 \mathrm{~m}$ e segundo Seeber (2003) varia apenas de centímetros, nas regiões planas, até $1 \mathrm{~m}$ em áreas montanhosas. De 
modo geral um modelo geoidal é menos acurado em áreas montanhosas com grande variação das camadas geológicas (Higgins, 1999). Como consequência do pequeno efeito da topografia, a superfície do geoide tem uma conformação muito mais suavizada que a superfície topográfica da mesma área. Portanto, para determinações de geoides locais, em áreas de poucas a algumas centenas de quilômetros quadrados, podem ser usadas superfícies geométricas relativamente simples, ajustadas a cada ponto da rede ao valor de N, como o plano inclinado, representado pela equação 5, e para áreas maiores superfícies polinomiais de graus $1 \mathrm{e}$ 2, como as equações 6 a 8 :
$\mathrm{z}_{\mathrm{i}}=\mathrm{aE}_{\mathrm{i}}+\mathrm{bN}_{\mathrm{i}}+\mathrm{c}$

$\mathrm{z}_{\mathrm{i}}=\mathrm{aE} \mathrm{E}_{\mathrm{i}}+\mathrm{bN}_{\mathrm{i}}+\mathrm{cE}_{\mathrm{i}} \mathrm{N}_{\mathrm{i}}+\mathrm{d}$

$\mathrm{z}_{\mathrm{i}}=\mathrm{aE}_{\mathrm{i}}+\mathrm{bN}_{\mathrm{i}}+\mathrm{cE}_{\mathrm{i}}^{2}+\mathrm{dNi}^{2}+\mathrm{e}$

$\mathrm{z}_{\mathrm{i}}=\mathrm{aE}_{\mathrm{i}}+\mathrm{bN}_{\mathrm{i}}+\mathrm{cN}_{\mathrm{i}} \mathrm{E}_{\mathrm{i}}+\mathrm{dE}_{\mathrm{i}}^{2}+\mathrm{eN}_{\mathrm{i}}^{2}+\mathrm{f}$

(Equação 5)

(Equação 6)

(Equação 7)

(Equação 8)
Em que: zi é a ondulação geoidal no ponto i;
Ei, Ni são as coordenadas UTM (Universal Transversa de Mercator) do ponto i; a, b, c, d, e, f são parâmetros determinados por ajustamento pelo MMQ (Método dos Mínimos Quadrados).

Esses procedimentos são adequados para a obtenção de um geoide local, cujos resultados do ajustamento são analisados e depurados dos eventuais erros grosseiros. Porém, na prática das empresas de engenharia é apenas realizada uma triangulação e uma interpolação linear, que permite gerar um mapa geoidal, como o mostrado na figura 1A, obtido com dados de ENGEFOTO (2009). A partir dos mesmos dados e com os modelos das equações 5, 6 e 8 foram gerados os mapas mostrados nas figuras $1 \mathrm{~B}, 1 \mathrm{C}$ e $1 \mathrm{D}$ respectivamente, com a finalidade de destacar as diferenças nas formas das superfícies obtidas. Evidentemente cada superfície gerada tem erros residuais diferentes, em cada ponto usado na modelagem, e a adoção de modelo não adequado vai introduzir erros significativos nas altitudes dos pontos a interpolar.
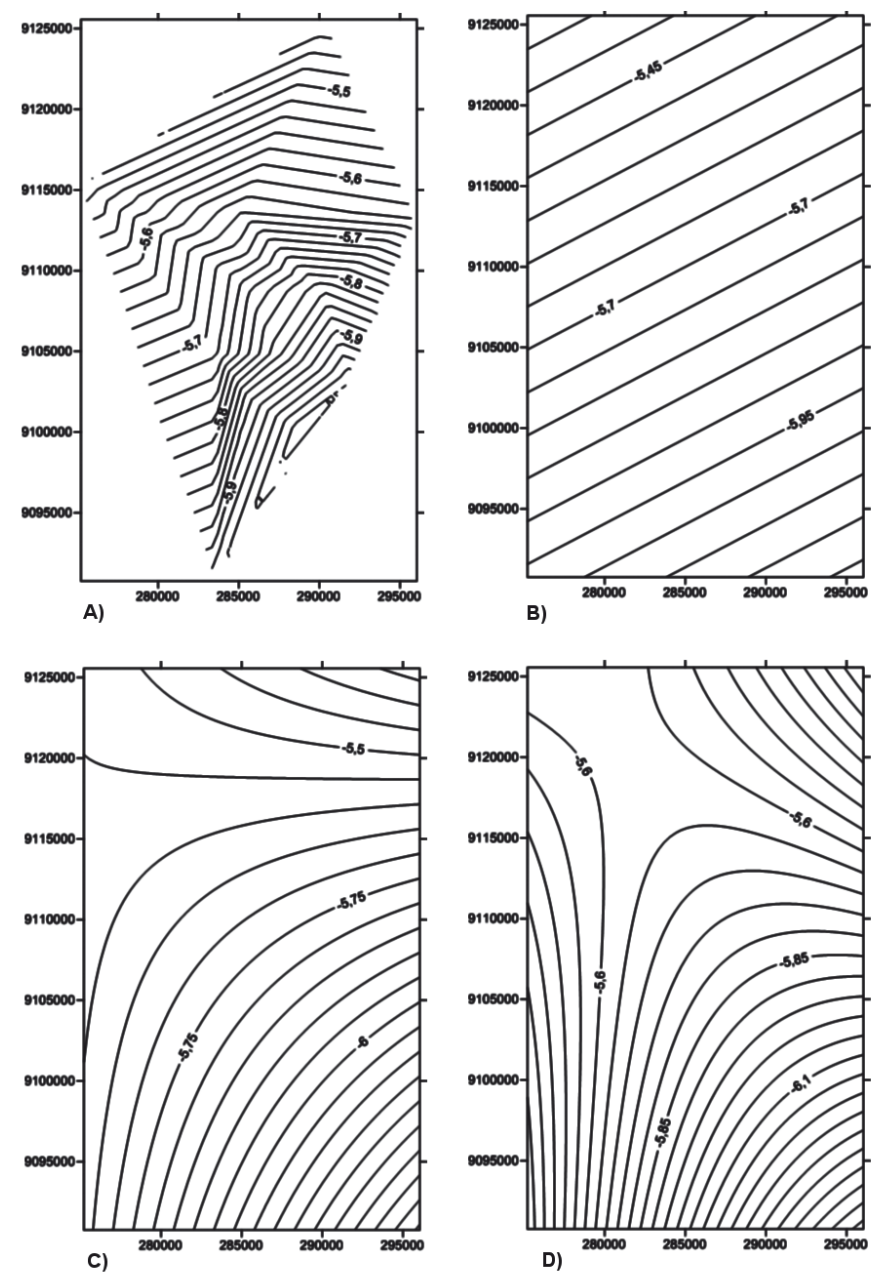

Figura 1. Superfícies de geoide local do tipo geométrico com diferentes interpoladores com dados de ENGEFOTO (2008). A) Interpolação linear em triangulação; B) Modelo com equação 5; C) Modelo com equação 6; D) Modelo com equação 8. Figure 1. Local geoid surfaces of the geometric type with different interpolators. A) Linear interpolation in triangulation; B) Model with equation 5; C) Model with equation 6; D) Model with equation 8. 


\subsubsection{Propagação de variâncias e precisões}

A acurácia de $\mathrm{N}$, ou do geoide, depende da distribuição e do número de pontos de controle usados, da modelagem do geoide do método de interpolação. Já a precisão da ondulação geoidal é uma composição das precisões das altitudes GNSS e do nivelamento geométrico, que em termos de variâncias, é dada pela equação 9 .

$$
\sigma_{\mathrm{N}}^{2}=\sigma_{\mathrm{h}}^{2}+\sigma_{\mathrm{H}}^{2}
$$

A precisão da altitude ortométrica, obtida posteriormente por interpolação, é o resultado da composição das precisões das altitudes GNSS, do nivelamento geométrico e da ondulação geoidal, dada por Ollikainen (1997):

$$
\sigma_{\Delta \mathrm{H}}^{2}=\sigma_{\mathrm{h}}^{2}+\sigma_{\mathrm{H}}^{2}+\sigma_{\mathrm{N}}^{2} \quad \text { (Equação 10) }
$$

Em que $\Delta \mathrm{H}$ é diferença de altitude entre o nivelamento geométrico e GNSS.

As equações 9 e 10 mostram que devem ser conhecidas as precisões dos nivelamentos e do geoide. Além disso, como as precisões são avaliadas de formas diferentes é necessário verificar o nível de confiança e origem dos dados utilizados para compatibilizá-los entre si. Por exemplo, se um valor de $\mathrm{N}$, de um geoide existente, tem precisão de $6 \mathrm{~mm}$ (um sigma) é estatisticamente provável que existam pontos com variação de $\mathrm{N}$ com até $3 \times 6$ $\mathrm{mm}=18 \mathrm{~mm}$.

\subsubsection{A ondulação geoidal e relações com obras de engenharia}

Os mapas de representação de ondulações geoidais normalmente usam isolinhas, cujos valores variam de poucos milímetros por quilômetro, nas regiões planas, a vários centímetros, em regiões de relevo muito ondulado (seção 2.1.5). A declividade da superfície em $\mathrm{mm} / \mathrm{km}$ pode ser obtida pela diferença de altitudes e pela distância horizontal entre os pontos avaliados, e varia de declividade máxima (linha C-D na figura 2, normal entre as curvas), a nula (linha A-B da figura 2, paralela às curvas).

Com o objetivo de conhecer e quantificar algumas declividades de geoides no Brasil, foram tomadas medidas nos geoides obtidos por Souza (2006) (p. 59, Fig. 3.8), Santos (2009) (p. 54, Fig. 3.6) e Silva (2012) (p. 84, Fig. 37), sendo encontradas declividades mínimas e máximas $(\mathrm{mm} / \mathrm{km})$ com valores de $13-37 \mathrm{~mm}, 2-26 \mathrm{~mm}$ e $10-20 \mathrm{~mm}$ respectivamente.

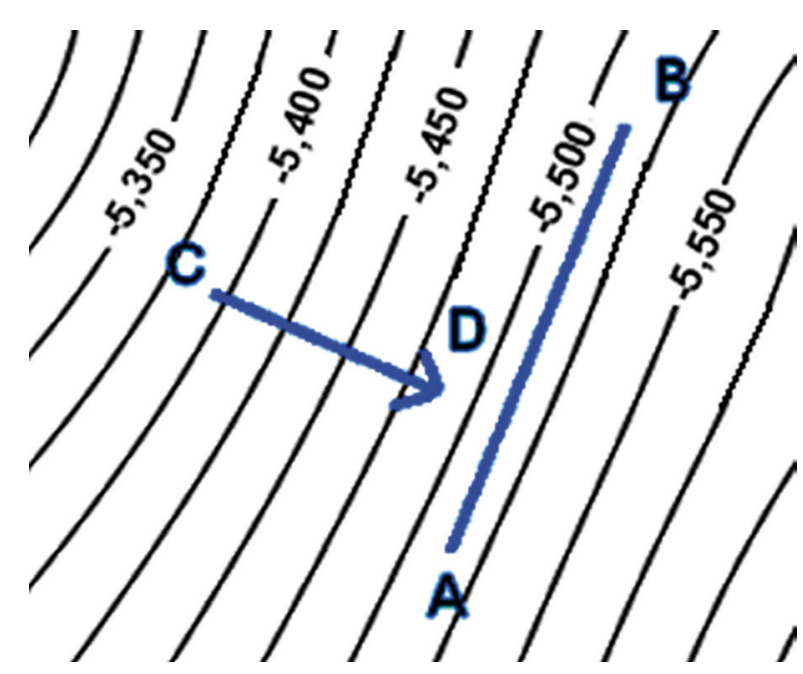

Figura 2. Declividades máxima (CD) e nula (AB) da ondulação geoidal.

Figure 2. Maximum (CD) and null (AB) slope of the geoid undulation.

Os valores mínimos e máximos das declividades da superfície do geoide são informações que podem ser usadas como referência na avaliação do erro tolerável em relação a um nivelamento geométrico, quando forem adotadas diretamente altitudes elipsoidais. Isto pode ser possível consultando um geoide nacional, como MAPGEO do IBGE, geoides regionais ou locais quando existentes. Para obras com pequenas dimensões como $100 \mathrm{~m}$, a maior declividade das ondulações dos exemplos citados acima para o Brasil (37 mm/ $\mathrm{km})$, implicaria apenas em 3,7 mm entre os extremos dessa obra. Mas se a declividade do geoide fosse de 10 $\mathrm{mm} / \mathrm{km}$ a diferença para a mesma obra seria de $1 \mathrm{~mm}$. Nestes casos, $3,7 \mathrm{~mm}$ e $1 \mathrm{~mm}$ são simples indicadores, para fins de comparação com as especificações do nivelamento geométrico exigido para a obra, mas a decisão pelo uso direto das altitudes elipsoidais implica também na análise das declividades ou de diferenças absolutas de alturas, como será mais discutido a seguir.

Para obras de engenharia com extensões de centenas de metros a quilômetros, além dos valores máximos e mínimos da declividade do geoide na área, os sentidos ascendente ou descendente da ondulação são outros dados a serem obtidos de geoides existentes. Essas informações são mais importantes principalmente quando a declividade é um fator crítico do projeto e deve ser obedecido rigorosamente durante a construção, como nos casos de canais e tubulações de drenagem de águas pluviais ou esgoto. Esta influência pode variar de favorável a desfavorável, conforme a direção da declividade da ondulação e da direção da obra, segundo a análise proposta a partir do exemplo a seguir. 
Um projeto de canal será implantado tomando como referência de altitudes a superfície elipsoidal. Nas figuras 3A e 3B o canal tem declividade de $1 \%$, sentido para esquerda, enquanto a ondulação geoidal tem declividade de $1 \%$ para a direita (A figura 3B é a mesma $3 \mathrm{~A}$ apenas girada para colocar a linha do geoide na horizontal). Como a declividade válida para escoamento de águas no canal deve ter como referência o geoide, a declividade efetiva é de $2 \%$, portanto maior que o projetado (Fig. 3B), e o nivelamento GNSS poderia ser diretamente utilizado. Na figura $3 \mathrm{C}$, tanto o projeto quanto o geoide tem declividades de $1 \%$ no mesmo sentido, para a direita, neste caso a obra fica com declividade efetiva nula em relação ao geoide (Fig. 3D) (A figura 3D é a mesma 3C apenas girada para que a linha do geoide fique na horizontal), e assim não se obteria o escoamento calculado. Em resumo, quando as declividades de obra e geoide são contrárias, o uso de nivelamento GNSS direto é favorável e sempre possível; quando são de mesmo sentido, o uso desse nivelamento é desfavorável, mas ainda pode ser possível usá-lo, dependendo da diferença ente os valores das declividades, da obra e da ondulação, e da especificação de precisão da obra.

As exigências e especificações de precisão de alturas e diferenças de altura em obras de engenharia variam de milímetros a metros, em valores relativos ou absolutos, entre as quais a tabela 4 mostra alguns exemplos. 0 exemplo na tabela que exige maior precisão do nivelamento, para garantir a vazão prevista de projeto, é de canal revestido com declividade de $0,010 \%$ ou $100 \mathrm{~mm} / \mathrm{km}$. 0 exemplo de menor precisão é de nivelamento para geração de mapa com curvas de nível de metro em metro.

As implicâncias do caso desfavorável (declividades de obra e ondulação geoidal de mesmo sentido) considerando valores mínimos de declividades e sentidos de escoamento, tomando como referência a ondulação máxima de $37 \mathrm{~mm} / \mathrm{km}$ encontrada em Souza (2006), são ilustradas com dois casos das obras. Para a obra 1, com declividade de $100 \mathrm{~mm} / \mathrm{km}$, canal revestido. Para a ondulação de $37 \mathrm{~mm} / \mathrm{km}$ a declividade útil da obra seria de $63 \mathrm{~mm} / \mathrm{km}$ (63\% da projetada), o que reduziria muito a vazão calculada de projeto. Para a obra 2, com declividade de $0,035 \%$, ou $350 \mathrm{~mm} /$ $\mathrm{km}$, a declividade efetiva seria ainda de $313 \mathrm{~mm} /$ km (89\% da projetada) e a redução da vazão pode não ser significativa. Nos dois casos a importância das reduções de vazões depende de outros fatores
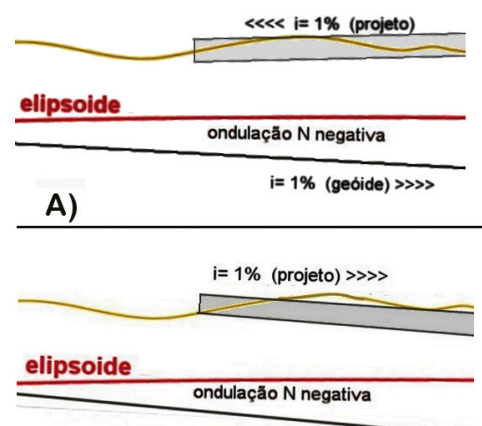

C)

$\mathrm{i}=1 \%($ geóide $) \gg \gg>$
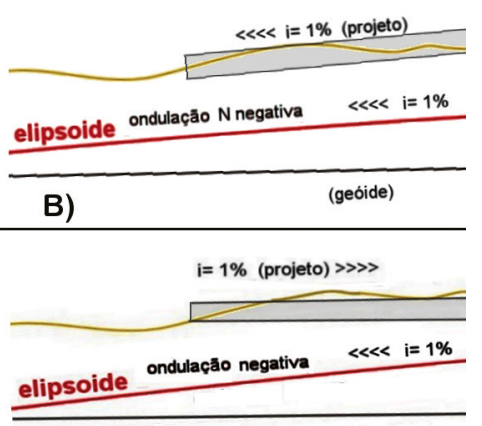

D)

(geóide)

Figura 3. Exemplo de declividades da ondulação geoidal e de obra em sentidos contrátrios. A) Elipsoide como referência; B) Geoide como referência; Declividades da ondulação e obra de mesmo sentido. C) Elipsoide como referência; D) Geoide como referência.

Figure 3. Example of slopes of geoid undulation and construction in opposite directions. A) Ellipsoid as reference; B) Geoid as reference; Slopes of geoid undulation and construction in same directions. C) Ellipsoid as reference; D) Geoid as reference

Tabela 4. Exemplos de algumas declividades e precisões mínimas em obras de engenharia.

Table 4. Examples of some minimum slopes and elevation precisions in engineering works

\begin{tabular}{lrrr}
\hline Exemplo de Obra & $\begin{array}{l}\text { Declividade mínima \%/ } \\
\text { Precisão de altitude }\end{array}$ & $\begin{array}{c}\text { Declividade } \\
\text { mm/km }\end{array}$ \\
\hline Canal revestido em concreto & $0,010 \%$ & 100 \\
Coletor de esgoto $\boldsymbol{\Phi} \mathbf{1 2 0 0} \mathbf{~ m m}$ & $0,035 \%$ & 350 \\
Tubulação de drenagem pluvial urbana & $0,500 \%$ & 5000 \\
Declividade transversal de rodovias & $2,000 \%$ & 20000 \\
Mapa escala 1:1000 com curvas de nível de 1m & 330 mm & - \\
\hline
\end{tabular}


do projeto não discutidos aqui.

Considerando ainda a declividade de $37 \mathrm{~mm} /$ $\mathrm{km}$ para os demais casos da tabela 4, com menores precisões, é razoável supor que as altitudes elipsoidais poderiam ser usadas diretamente, mas devem ser adotados todos os cuidados necessá rios no levantamento para controlar os eventuais erros nas medições com GNSS, conforme discutido em 2.1.2. Para os casos de obras de alta precisão a análise deve ser mais criteriosa e apenas no caso favorável (ondulações do geoide e do projeto de sentido contrários) é possível usar o nivelamento GNSS diretamente com segurança.

\section{2 levantamentos e processamentos}

Os levantamentos efetuados simularam as condições normais adotadas em obras de engenharia com tempos de rastreio curtos (15 min), em área com 2,13 $\mathrm{km}^{2}$. Inicialmente foram realizados um nivelamento geométrico e um GNSS, necessários para gerar um modelo de geoide. $\mathrm{Na}$ etapa de processamento dos dados foram percebidos erros grosseiros e os nivelamentos GNSS de vários pontos foram repetidos. Com as repetições de rastreios foram analisadas as discrepâncias entre os dados adquiridos por receptores diferentes no mesmo dia, entre rastreios em dias diferentes e processados por softwares diferentes. A tabela 5 mostra os pontos com as sessões de rastreio. A figura 4 mostra a área e entorno da UFPE e os pontos levantados.

\subsubsection{Nivelamentos}

As altitudes ortométricas foram obtidas de nivelamento de precisão com nível digital e mira com código de barras, em circuitos fechados, cujo ajustamento atingiu precisão de cerca de $1 \mathrm{~mm}$ e assim essas altitudes foram consideradas exatas (coluna H da Tab. 5).

Os nivelamentos GNSS usaram métodos rápidos e simples como os recomendáveis para obras de engenharia mas alguns pontos apresentaram discrepâncias muito significativas quando analisados tiveram de ser repetidos. Um conjunto de 18 pontos foi rastreado de dois modos: a) com modo estático rápido, sessões de $15 \mathrm{~min}$, taxa de $15 \mathrm{~s}$, base na estação RECF da RBMC (Rede Brasileira da Monitoramento Contínuo dos Sistemas GNSS) , situada dentro do Campus da UFPE (Universidade Federal de Pernambuco) e linhas de base máxima de $735 \mathrm{~m}$; b) uma parte foi rastreada com método RTK (Real Time Kinematic) com base na estação UFPE, no prédio do CTG (Centro de Tecnologias e Geociências).

Tabela 5. Sessões de rastreio e altitudes ortométricas dos pontos levantados.

Table 5. Tracking sessions and point orthometric elevations.

\begin{tabular}{|c|c|c|c|c|c|c|}
\hline ESTAÇÃO & $\begin{array}{c}\text { Dia } \\
\text { 30/04/11 } \\
\text { GTR1 }\end{array}$ & $\begin{array}{l}\text { Dia } \\
\text { 30/04/11 } \\
\text { Hiper }\end{array}$ & $\begin{array}{c}\text { Dia } \\
\text { 14/05/11 } \\
\text { Hiper }\end{array}$ & $\begin{array}{c}\text { Dia } \\
\text { 11/06/11 } \\
\text { Hiper }\end{array}$ & $\begin{array}{c}\text { Dia } \\
\text { 08/06/11 } \\
\text { RTK }\end{array}$ & $\begin{array}{l}\text { Alt. Ort. H } \\
\text { (m) }\end{array}$ \\
\hline RECF (base) & $\mathrm{X}$ & $\mathrm{X}$ & $X$ & $\mathrm{X}$ & & 25,911 \\
\hline UFPE (base) & & & & & $\mathrm{X}$ & 49,808 \\
\hline M021 & $\mathrm{X}$ & $\mathrm{X}$ & $\mathrm{X}$ & $\mathrm{X}$ & $X$ & 8,334 \\
\hline M022 & $\mathrm{X}$ & $\mathrm{X}$ & & & & 10,123 \\
\hline M023 & $\mathrm{X}$ & $\mathrm{X}$ & & & & 8,942 \\
\hline M024 & $\mathrm{X}$ & $\mathrm{X}$ & & & & 8,954 \\
\hline M030 & & & & $\mathrm{X}$ & & 8,954 \\
\hline M032 & & & $\mathrm{X}$ & $\mathrm{X}$ & & 9,143 \\
\hline M033 & & & $\mathrm{X}$ & $\mathrm{X}$ & $\mathrm{X}$ & 9,331 \\
\hline BRENNAND & & & & $\mathrm{X}$ & $X$ & 12,204 \\
\hline ELÉTRICA & & & & $\mathrm{X}$ & $X$ & 9,345 \\
\hline EXÉRCITO & & & & $\mathrm{X}$ & $\mathrm{X}$ & 9,454 \\
\hline IGREJA & & & & $\mathrm{X}$ & $\mathrm{X}$ & 10,688 \\
\hline ITEP & & & & $\mathrm{X}$ & $\mathrm{X}$ & 8,590 \\
\hline LAGO & & & & $\mathrm{X}$ & $\mathrm{X}$ & 9,711 \\
\hline RN3641A & $\mathrm{X}$ & $\mathrm{X}$ & & & & 11,382 \\
\hline RN3641B & $\mathrm{X}$ & $\mathrm{X}$ & $\mathrm{X}$ & & & 9,221 \\
\hline RN3641C & $\mathrm{X}$ & $\mathrm{X}$ & $\mathrm{X}$ & & & 9,534 \\
\hline
\end{tabular}




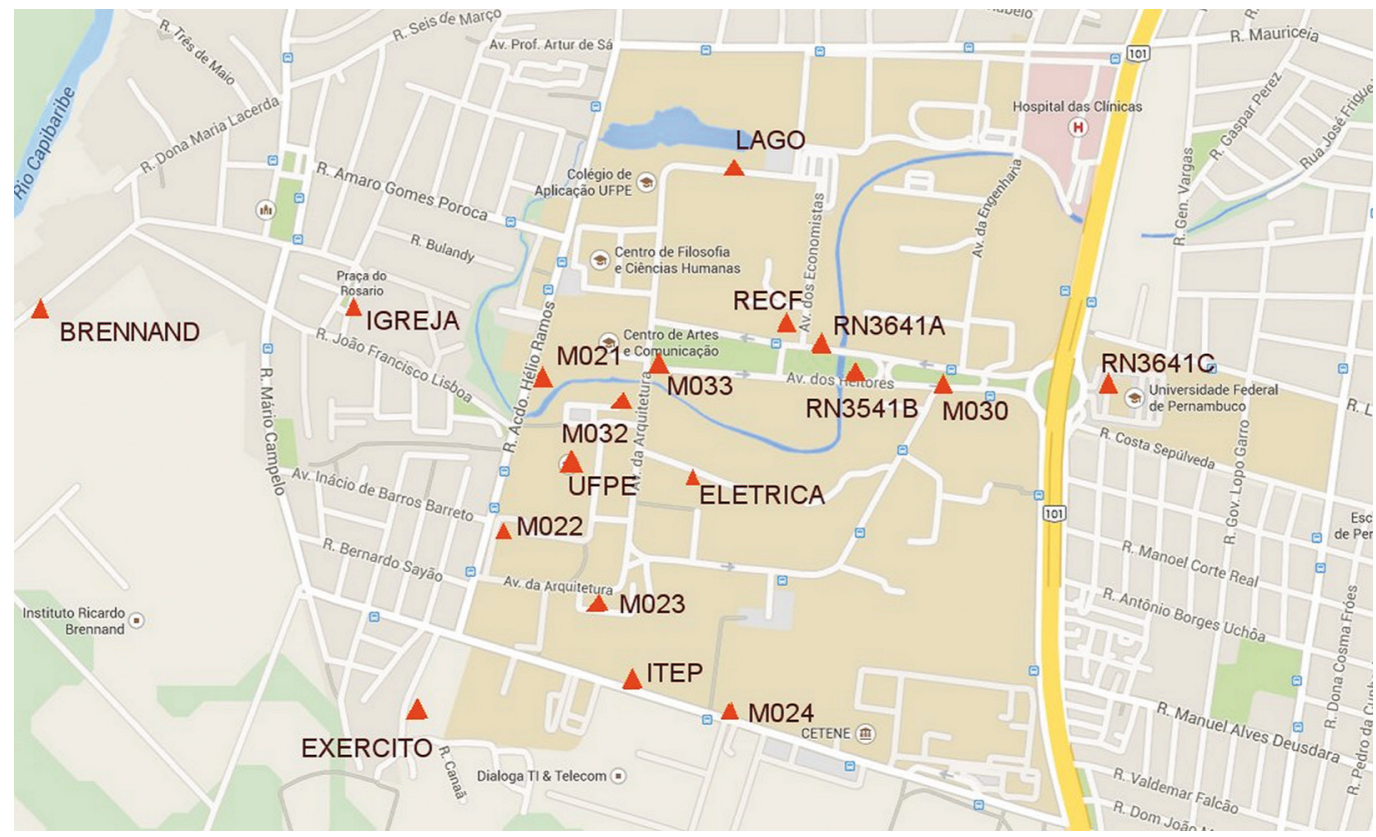

Figura 4. Área da UFPE com os pontos GNSS levantados (Fonte do mapa: Googlemaps).

Figure 4. UFPE area with the surveyed GNSS points (Map source: Googlemaps).

\subsubsection{Processamento dos rastreios}

Os processamentos dos rastreios no modo estático foram realizados nos softwares EZsurv 2.4, Topcon Tools 8.2 e GNSS Solutions e os processamentos do RTK no Topcon Tools.

\subsubsection{Geração do geoide geométrico local}

Todos os pontos rastreados relacionados na tabela 4 foram usados para a geração de modelo de geoide local utilizando o software Astgeotop, desenvolvido pelo Prof. Silvio Jackes Garnés. O Astgeotop é constituído por um conjunto de aplicações geodésicas entre elas a geração de geoides. Nessa função utiliza um tipo de validação cruzada, em que cada ponto da rede é colocado como ponto fixo que pertence à superfície a ser testada. Em seguida os parâmetros do tipo da superfície escolhida são obtidos de ajustamento pelo MMQ utilizando os demais pontos e finalmente são analisadas as discrepâncias entre as altitudes originais e a nova interpolada. Com isto é possível realizar testes de identificação de erros grosseiros. 0 processamento é concluido com a geração de uma lista com as coordenadas tri dimensionais ajustadas dos pontos, que pode ser usada como entrada em softwares de interpolação e ser gerado o mapa com as isolinhas das ondulações.

0 modelo de superfície usado foi o plano inclinado da equação 5, apenas com a alteração de coordenadas em UTM para geodésicas.

\section{Resultados}

\subsection{Processamentos de dados obtidos no mesmo dia com receptores diferentes}

Para comparação entre os rastreios no mesmo dia (30/04/2011) com receptores diferentes foram utilizados um receptor GTR-1 (marca Sightgps) com L1 e um Hipe-Lite (marca Topcon) com L1/L2. Todos os dados obtidos com o GTR-1 foram processados, mas as discrepâncias com os outros rastreios foram muito significativas, mesmo com linhas de base curtas e soluções dadas no relatório com de fixação das ambiguidades, e por este motivo não foram utilizados nas demais fases do trabalho. Os motivos dos erros não foram detectados.

\subsection{Processamentos com programas diferentes $e$ dias diferentes}

Os processamentos dos mesmos dados em programas diferentes permitem comparar os desempenhos que refletem as diferenças dos algoritmos de ajustamento, resolução de ambiguidades, pesos das observações, injunções das estações, e modelos atmosféricos. Já os processamentos de sessões de rastreio em dias diferentes mostram as influências de diferenças de constelação dos satélites e diferenças atmosféricas. Foram realizadas várias seções de rastreio com os métodos estático e RTK. Porem por não ser possível discutir aqui todos os dados obtidos por Silva (2012) foram esco- 
lhidos cinco pontos, rastreados em dois dias diferentes e processados por três softwares diferentes, que ilustram bem as discrepâncias reais encontradas no conjunto completo de dados.

Na tabela 6 estão os resultados das altitudes de processamentos com softwares EZsurv 2.4, Topcon Tools 8.4 e GNSS Solutions, dos cinco pontos escolhidos. As precisões das altitudes desses pontos dadas pelos relatórios de processamento variaram entre $0,001 \mathrm{~m}$ e $0,084 \mathrm{~m}$, com médias entre 0,007 $m$ e 0,024 m enquanto os desvios padrões calculados dos três resultados variam entre $\pm 0,029 \mathrm{~m} \mathrm{e} \pm$ $0,093 \mathrm{~m}$, o que confirma que as precisões informadas pelos softwares de processamento GNSS são mais otimistas que a realidade, neste caso cerca de quatro vezes. As diferenças entre EZSurv e Topcon Tools são menores entre si (média da coluna 4 de 0,023 ) quando comparados com que os resultados do GNSS Solutions (médias 0,075 e 0,052 das colunas 5 e 6). Isto indica que o EZSurv e Topcon Tools têm resultados mais próximos entre si e o GNSS Solutions os mais discrepantes. As discrepâncias absolutas entre dias diferentes variam de $0 \mathrm{~cm}$ (RN3641B com o EZSurv) a $27 \mathrm{~cm}$ (RN3641C com o GNSS Solutions). A maior discrepância entre softwares ocorreu também no ponto RN3641C com valor de 22,5 cm entre o EZSurv e GNSS Solutions.
Para fins de comparação com os padrões de nivelamento geométrico a tabela 7 apresenta os valores do indicador $\mathrm{a}_{\mathrm{gps}}$ calculados pela equação 9, usando como distância $\mathrm{k}$ a linha de base da tabela 6. Na parte superior da tabela estão as diferenças absolutasdas altitudes entre softwares convertidas em $\mathrm{a}_{\text {gps. }} \mathrm{Na}$ coluna 1 (EZSurv - Topcon) $\mathrm{a}_{\mathrm{gps}}$ varia de 7 a $39 \mathrm{~mm}$, mas os valores aumentam para $211 \mathrm{~mm}$ na colunas 2 (EZSurv - GNSS) e para 182 na coluna 3 (GNSS-Topcon). Na parte inferior da tabela 7 estão os valores de $\mathrm{a}_{\text {gps }}$ relativos às diferenças entre os dias 30/04 e 14/05, que variaram de 0 a $175 \mathrm{~mm}$ para o EZSurv, de 2 a $171 \mathrm{~mm}$ Topcon Tools, 13 a $329 \mathrm{~mm}$ para o GNSS Solutions.

Os valores de $\mathrm{a}_{\mathrm{gps}}$ da tabela 7 que são bem representativos dos demais do conjunto dos dados obtidos por Silva (2012). A magnitude significativa de discrepâncias obtidas com nivelamento GNSS também pode ser encontrada em outros trabalhos publicados sobre modelagem de geoides locais, que usaram rastreios com tempos rápidos de alguns minutos, ou até maiores que uma hora. Porém a identificação das discrepâncias apenas é possível quando nos dados estão tabulados pontos com mais de uma ocupação e suas respectivas altitudes.

As discrepâncias da tabela 7 são indicativas

Tabela 6. Resultados de processamentos com softwares diferentes e pontos rastreados em dois dias diferentes. Altitudes GNSS e unidades em metro. Linha de base para estação RECF.

Table 6. Results of processing with different software and points collected on two different days. GNSS elevations and units in meter. Baseline for the RECF station.

\begin{tabular}{|c|c|c|c|c|c|c|c|c|}
\hline Ponto & Data & $\begin{array}{c}1 \\
\text { EZsurv }\end{array}$ & $\begin{array}{c}2 \\
\text { Topcon }\end{array}$ & $\begin{array}{c}3 \\
\text { Gnss }\end{array}$ & $\begin{array}{c}4 \\
\text { Dif } 1-2\end{array}$ & $\begin{array}{c}5 \\
\text { Dif 1-3 }\end{array}$ & $\begin{array}{c}6 \\
\text { Dif } 2-3\end{array}$ & $\begin{array}{l}\text { LB } \\
(\mathrm{m})\end{array}$ \\
\hline \multirow{3}{*}{ M021 } & $30 / 4 / 2011$ & 2,527 & 2,506 & 2,440 & 0,021 & 0,087 & 0,066 & \\
\hline & $14 / 5 / 2011$ & 2,646 & 2,622 & 2,551 & 0,024 & 0,095 & 0,071 & 460 \\
\hline & Diferença & $-0,119$ & $-0,116$ & $-0,111$ & & & & \\
\hline \multirow{3}{*}{ RN3641B } & $30 / 4 / 2011$ & 3,493 & 3,485 & 3,411 & 0,008 & 0,082 & 0,074 & \\
\hline & $14 / 5 / 2011$ & 3,493 & 3,479 & 3,402 & 0,014 & 0,091 & 0,077 & 191 \\
\hline & Diferença & 0,000 & 0,006 & 0,009 & & & & \\
\hline \multirow[t]{3}{*}{ RN3641C } & $30 / 4 / 2011$ & 3,799 & 3,793 & 3,931 & 0,006 & $-0,132$ & $-0,138$ & \\
\hline & $14 / 5 / 2011$ & 3,884 & 3,787 & 3,659 & 0,097 & 0,225 & 0,128 & 682 \\
\hline & Diferença & $-0,085$ & 0,006 & 0,272 & & & & \\
\hline \multirow[t]{3}{*}{ M032 } & $14 / 5 / 2011$ & 3,435 & 3,413 & 3,374 & 0,022 & 0,061 & 0,039 & \\
\hline & $11 / 6 / 2011$ & 3,429 & 3,414 & 3,365 & 0,015 & 0,064 & 0,049 & 317 \\
\hline & Diferença & 0,006 & $-0,001$ & 0,009 & & & & \\
\hline \multirow{4}{*}{ M033 } & $14 / 5 / 2011$ & 3,617 & 3,604 & 3,523 & 0,013 & 0,094 & 0,081 & \\
\hline & $11 / 6 / 2011$ & 3,614 & 3,607 & 3,529 & 0,007 & 0,085 & 0,078 & 198 \\
\hline & Diferença & 0,003 & $-0,003$ & $-0,006$ & & & & \\
\hline & & & & média & 0,023 & 0,075 & 0,052 & \\
\hline
\end{tabular}


Tabela 7. Valores em $\mathrm{mm}$ de $\mathrm{a}_{\mathrm{gps}}$ relativos à tabela 6.

Table 7.Values in $\mathrm{mm}$ of $a_{\text {gps }}$ relative to table 6.

\begin{tabular}{|c|c|c|c|}
\hline \multicolumn{4}{|c|}{$\mathrm{a}_{\mathrm{gps}}$ entre os softwares dia $30 / 04 / 2011$} \\
\hline & Dif* $1-2$ & Dif*1-3 & Dif* 2-3 \\
\hline M021 & 31 & 128 & 97 \\
\hline RN3641B & 18 & 188 & 169 \\
\hline RN3641C & 7 & 160 & 167 \\
\hline M032 & 39 & 108 & 69 \\
\hline M033 & 29 & 211 & 182 \\
\hline \multicolumn{4}{|c|}{$a_{\text {gps }}$ entre os dias $30 / 04$ e $14 / 05$} \\
\hline & Com EZsurv & Com Topcon & $\begin{array}{l}\text { Com } \\
\text { GNSS }\end{array}$ \\
\hline M021 & 175 & 171 & 164 \\
\hline RN3641B & 0 & 14 & 21 \\
\hline RN3641C & 103 & 7 & 329 \\
\hline M032 & 11 & 2 & 16 \\
\hline M033 & 7 & 7 & 13 \\
\hline
\end{tabular}

*1-EZsurv, 2-Topcon tools, 3-GNSS Solutions

das magnitudes dos erros do nivelamento GNSS e podem sinalizar os tipos de obras em que são toleráveis com base nas precisões requeridas na equivalência com o nivelamento geométrico. Entre dias diferentes foi detectada variação absoluta $\mathrm{a}_{\mathrm{gps}}$ de 0 a $329 \mathrm{~mm}$ (Tab. 7). Supondo que esse levantamento seja para uma obra com declividade de $0,035 \%$ (350 mm/km, ou diferença de cota de $350 \mathrm{~mm}$ em $1 \mathrm{~km}$ ), aquele valor de $329 \mathrm{~mm}$ é muito próximo do especificado para a obra e não se poderia usar a altitude elispoidal diretamente, no caso de declividade de ondulação geoidal desfavorável, conforme discutido na seção 2.1.6. Mas para uma obra com declividade bem maior, como de 0,50\% (5.000 $\mathrm{mm} / \mathrm{km}$ ) ou mapeamento com curvas de nível com intervalos de $1,0 \mathrm{~m}$, em que o desvio padrão especificado para os pontos de teste é de $330 \mathrm{~mm}$, a diferença de $329 \mathrm{~mm}$ pode ser considerada adequada para ambos os casos. As obras aqui foram consideradas com extensão de $1 \mathrm{~km}$ para facilitar as comparações de declividades e diferenças absolutas de altitudes.

Estes exemplos de uso direto do nivelamento GNSS podem ser enquadrados de modo geral em obras de média e baixa precisão.

\subsection{Levantamentos RTK}

Os levantamentos com RTK foram realizados com dois pares de receptores Hiper-lite, um da
UFPE e outro do IFPE, com base no ponto UFPE (situado na cobertura do prédio do CTG). No processamento as altitudes foram obtidas sem nenhuma correção de modelo de geoide global ou nacional (Tab. 8). As diferenças entre as altitudes dos pontos variam entre $-0,002 \mathrm{~m}$ e $-0,023 \mathrm{~m}$ para o receptor da UFPE e de $-0,002 \mathrm{~m}$ a $-0,124 \mathrm{~m}$ para o receptor do IFPE. 0 valor do ponto BRENAND é superior ao esperado para o RTK à distância cerca de $1000 \mathrm{~m}$. Os desvios padrões das diferenças foram 0,019 m e 0,039 m e médias de $-0,021$ m e - $-0,022$ $\mathrm{m}$ respectivamente para UFPE e IFPE. Retirando o ponto BRENAND as médias e desvios padrões diminuem e variam entre 1 e $2 \mathrm{~cm}$ absolutos que para uma distância média de 551,11 m fornece um valor $\mathrm{a}_{\mathrm{gps}}$ de 13 a $26 \mathrm{~mm}$. Todos os valores de $\mathrm{a}_{\mathrm{gps}}$ relativos à tabela 8 estão na tabela 9, que mostra também médias e desvios padrões de todas as discrepâncias com e sem o ponto BRENAND.

Comparando-se os valores da tabela $9 \mathrm{com}$ a classe de nivelamento IIN (a=20 mm) a maioria dos pontos está abaixo da tolerância em uma das três comparações exceto os pontos EXERCITO e ITEP. Entre os valores das colunas H-h1 e H-h2 os pontos LAGO e BRENAND apresentam valores maiores que três desvios padrões, indicando que houve algum erro durante seus rastreios, como multicaminho ou erro de reocupação.

$\mathrm{O}$ intervalo de $\mathrm{a}_{\mathrm{gps}}$ com os rastreios RTK variou de $2 \mathrm{~mm}$ a $111 \mathrm{~mm}$, com média geral de $27,6 \mathrm{~mm}$ e desvio padrão geral de $30,4 \mathrm{~mm}$. Caso seja tomado 
Tabela 8. Altitudes ortométricas em metros obtidas com RTK pelos receptores UFPE e IFPE. Table 8. Orthometric elevations in meters obtained with RTK by UFPE and IFPE receptors.

\begin{tabular}{|c|c|c|c|c|c|c|c|}
\hline PONTO & $\begin{array}{l}\text { ALT ORT } \\
\text { (H) (m) }\end{array}$ & $\begin{array}{l}\text { UFPE (h1) } \\
\text { (m) }\end{array}$ & $\begin{array}{l}\text { IFPE } \\
\text { (h2) (m) }\end{array}$ & $\begin{array}{l}\text { (h1-h2) } \\
\text { (m) }\end{array}$ & $\begin{array}{l}\text { (H-h1) } \\
\text { (m) }\end{array}$ & $\begin{array}{l}(\mathrm{H}-\mathrm{h} 2) \\
(\mathrm{m})\end{array}$ & $\begin{array}{l}\text { Linha } \\
\text { Base (m) }\end{array}$ \\
\hline ELÉTRICA & 9,345 & 9,352 & 9,349 & 0,003 & $-0,007$ & $-0,004$ & 401,25 \\
\hline LAGO & 9,711 & 9,771 & 9,733 & 0,038 & $-0,060$ & $-0,022$ & 291,52 \\
\hline M033 & 9,331 & 9,336 & 9,325 & 0,011 & $-0,005$ & 0,006 & 197,51 \\
\hline M021 & 8,334 & 8,357 & 8,353 & 0,004 & $-0,023$ & $-0,019$ & 459,04 \\
\hline IGREJA & 10,688 & 10,706 & 10,694 & 0,012 & $-0,018$ & $-0,006$ & 781,40 \\
\hline BRENAND & 12,204 & 12,244 & 12,328 & $-0,084$ & $-0,040$ & $-0,124$ & 1409,00 \\
\hline EXERCITO & 9,454 & 9,469 & 9,456 & 0,013 & $-0,015$ & $-0,002$ & 983,47 \\
\hline \multirow[t]{3}{*}{ ITEP } & 8,590 & 8,592 & 8,599 & $-0,007$ & $-0,002$ & $-0,009$ & 743,56 \\
\hline & \multicolumn{3}{|r|}{ MEDIA } & $-0,001$ & $-0,021$ & $-0,022$ & 658,34 \\
\hline & \multicolumn{3}{|r|}{ D P } & 0,034 & 0,019 & 0,039 & \\
\hline \multirow{2}{*}{\multicolumn{2}{|c|}{ SEM O PONTO BRENAND }} & \multirow{2}{*}{\multicolumn{2}{|c|}{$\begin{array}{l}\text { MEDIA } \\
\text { DP }\end{array}$}} & 0,011 & $-0,019$ & $-0,008$ & 551,11 \\
\hline & & & & 0,013 & 0,018 & 0,009 & \\
\hline
\end{tabular}

Tabela 9. Valores da constante $\mathrm{a}_{\mathrm{gps}}$ relativos à tabela 8 .

Table 9. Values of the $a_{g p s}$ constant to table 8

\begin{tabular}{lrrr}
\hline PONTO & $\mathrm{a}_{\mathrm{gps}} \mathrm{h} 1-\mathrm{h} 2(\mathrm{~mm})$ & $\mathrm{a}_{\mathrm{gps}} \mathrm{H}-\mathrm{h} 1(\mathrm{~mm})$ & $\mathrm{a}_{\mathrm{gps}} \mathrm{H}-\mathrm{h} 2(\mathrm{~mm})$ \\
\hline ELETRICA & 5 & 11 & 6 \\
LAGO & 70 & 111 & 41 \\
M033 & 25 & 11 & 14 \\
M021 & 6 & 34 & 28 \\
IGREJA & 14 & 20 & 7 \\
BRENAND & 71 & 34 & 105 \\
EXERCITO & 13 & 15 & 2 \\
ITEP & 8 & 2 & 10 \\
\hline Média & 26,5 & 29,8 & 26,6 \\
DP & 26,1 & 32,4 & 32,0 \\
Média geral & $\mathbf{2 7 , 6}$ DP Geral & $\mathbf{3 0 , 4}$ \\
\hline Média sem BRENAND & $\mathbf{2 1 , 6}$ DP Geral & $\mathbf{2 5 , 3}$ \\
\hline
\end{tabular}

como referência de precisão o desvio padrão 30,4 $\mathrm{mm}$, e comparados com os valores de referência para $1 \mathrm{~km}$ das obras da tabela 4 , com os devidos cuidados, poderia ser usado o nivelamento GNSS com RTK. Porém o maior valor, $111 \mathrm{~mm}$, para uma obra de canal com declividade $100 \mathrm{~mm} / \mathrm{km}$ está acima do limite, a não ser que as declividades da obra e do geoide tenham sentidos contrários (Fig. 3A e 3B). No entanto para obras de coletores de esgoto ou águas pluviais com declividades de 350 $\mathrm{mm} / \mathrm{km}$ a declividade efetiva, na pior situação, seria de $239 \mathrm{~mm}$ e a redução de vazão talvez seja aceitável. Essa alteração na vazão em outras situa- ções poderia ser de aumento, sendo necessário em qualquer caso uma verificação dos cálculos do projeto. É importante salientar que nas fórmulas de cálculo de vazão, entram vários parâmetros cujos intervalos de variação são muito significativos, e muitos são estimados, de modo que a vazão real pode sofrer variações maiores que as provocadas por pequenas alterações na declividade.

\subsection{Geração do geoide geométrico local}

Os geoides foram gerados com cada um do conjunto dos dados levantados da tabela 5 separa- 
damente e as discrepâncias existentes foram indicadas nos relatórios como sendo erros grosseiros. A figura 5 mostra um desses geoides, com uma depressão, indicando graficamente que a ondulação geoidal não apresenta o aspecto esperado de variação uniforme das declividades como discutido na seção 2.1.4. As curvas fechadas e outras muito desalinhadas são possíveis indícios da modelagem não adequada do geoide.

Após vários testes usando o software Astgeotop foi possível escolher um conjunto de dados que apresentou maior consistência e que coincidiu com os levantamentos processados com o Topcon, num total de 16 pontos. Após eliminação de três pontos com indicação de erros grosseiros, os 13 restantes foram processados no software Surfer e foi gerado o mapa geoida 1 mostrado na figura 6. Na figura 6 as isolinhas estão separadas de aproximadamente $150,0 \mathrm{~m}$ e a diferença de ondulação geoidal entre elas é de $5 \mathrm{~mm}$, que equivale à declividade máxima de $33 \mathrm{~mm} / \mathrm{km}$, ou de $0,0033 \%$.

O resumo das estatísticas para os resíduos entre as ondulações geoidais de entrada e as obtidas pela superfície da equação 4 segundo o relatório do Astgetop estão na tabela 10. A precisão está definida pelo EMQ de $6 \mathrm{~mm}$ e assim o geoide pode ser considerado de alta precisão.

Transformando o EMQ de $6 \mathrm{~mm}$, com $68 \%$ de confiabilidade, para o padrão do nivelamento geométrico de $100 \%$, em termos práticos o valor passa para $18 \mathrm{~mm}$, que é bem próximo dos $20 \mathrm{~mm} /$ $\mathrm{km}$ exigidos para obras comuns de engenharia pela classe IIN da ABNT. Porém esse geoide para ser usado rigorosamente para transformação de altitude elipsoidal para ortométricas ainda será necessário considerar a precisão da medição com GNSS dos novos pontos medidos para a obra.

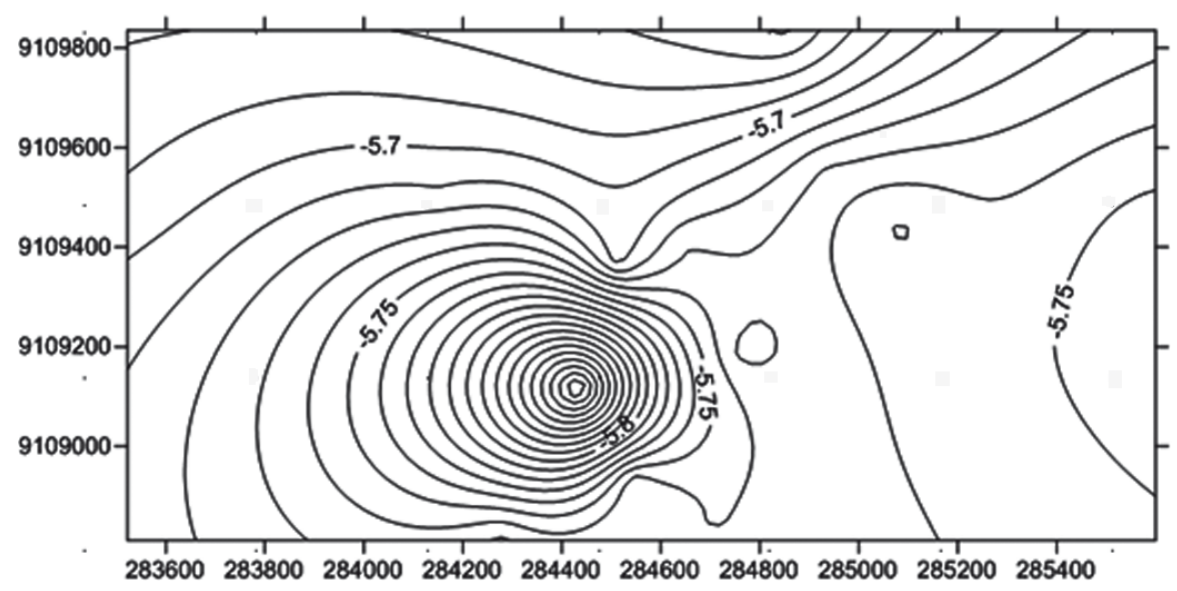

Figura 5. Exemplo de geoide obtido com erros grosseiros. Fonte: Silva (2012).

Figure 5. Example of geoid obtained with gross errors. Source: Silva(2012).

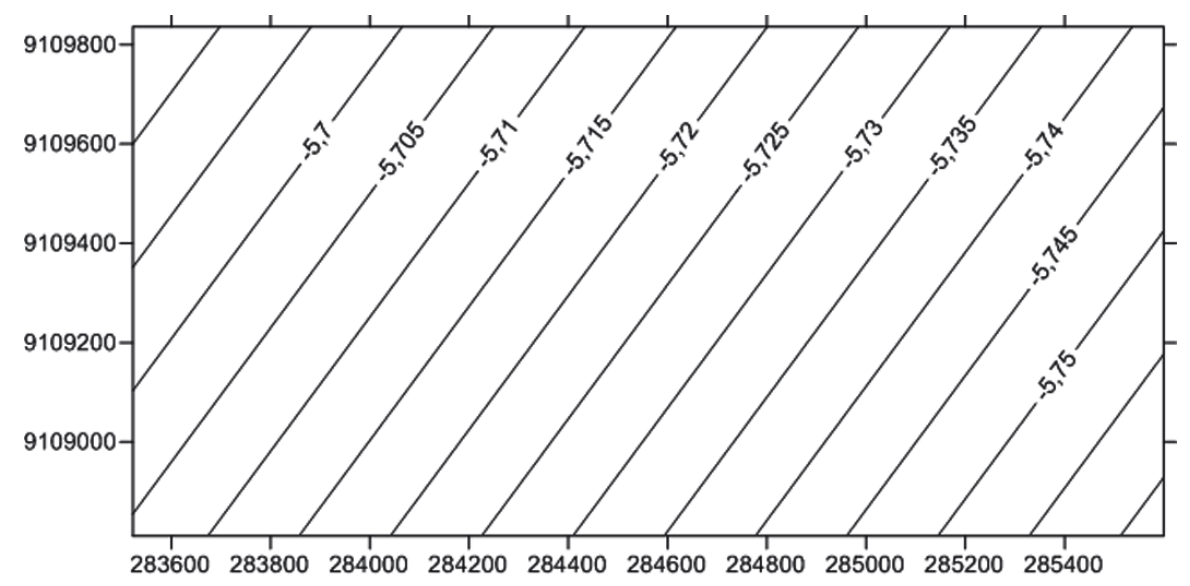

Figura 6. Geoide local final da área da UFPE.

Figure 6. Final Geoid of the UFPE area. 
Tabela 10. Resumo do relatório de processamento do geoide final obtido para a UFPE. Table 10. Summary of the final geoid processing report obtained for UFPE.

\begin{tabular}{|c|c|}
\hline Estatística & valor \\
\hline Média & $-0,001 m$ \\
\hline Média absoluta & $0,005 \mathrm{~m}$ \\
\hline Discrepância máxima (ponto Exército) & $0,007 \mathrm{~m}$ \\
\hline Discrepância mínima (ponto M021) & $-0,016 m$ \\
\hline EMQ (Erro Médio Quadrático) & $0,006 \mathrm{~m}$ \\
\hline
\end{tabular}

\section{Discussão dos resultados}

\subsection{Levantamentos estáticos rápidos}

Foram identificadas discrepâncias de altitudes muito significativas para um mesmo ponto. Um dos motivos pode ser atribuído ao pequeno tempo de rastreio em que as coordenadas podem ser afetadas por erros de multicaminho (ICSM, 2014). De modo geral houve essas discrepâncias entre sessões de rastreio diferentes, com equipamentos diferentes e processados em softwares diferentes. Entre softwares diferentes houve essas diferenças em pontos com solução fixa ou flutuante. Mesmo com solução fixa algumas altitudes apresentaram valores além do intervalo esperado a partir dos desvios padrões dos relatórios de ajustamento.

As ordens de grandeza do indicador $\mathrm{a}_{g p s}$ de modo geral indicaram valores significativamente maiores que as especificações do nivelamento geométrico para obras de engenharia definidas pela ABNT, para a Classe NII. Como o nivelamento geométrico tem procedimentos bem consolidados na prática diária e tem alta confiabilidade é sugerido que no nivelamento GNSS haja procedimento similar, com a repetição de medição. No nivelamento geométrico o erro de um lance de nivelamento será propagado para o seguinte e só será descoberto no contra nivelamento. Em um circuito de nivelamento GNSS cada medição é independente da anterior e posterior, só tendo relação com a base, portanto o erro de um ponto não se propaga para o ponto vizinho.

As discrepâncias entre os rastreios e processamentos convertidas para o indicador $\mathrm{a}_{\text {gps }}$ variaram de zero a $329 \mathrm{~mm}$ sem ser possível detectar algum padrão característico de comportamento dessas ocorrências.

\subsection{Levantamentos $R T K$}

Os levantamentos com RTK apresentaram as constantes $\mathrm{a}_{\mathrm{gps}}$ melhores que os nivelamentos GNSS com rastreio estático rápido, mas mesmo assim alguns pontos extrapolaram os indicadores em mais de três desvios padrões, portanto o uso direto de RTK deve ser feito com os devidos cuidados, incluindo medições de verificação. Segundo Willgalis et al. (2003) apenas uma determinação com RTK não é confiável porque algumas vezes a as ambiguidades são fixadas com erro, portanto é essencial uma medição de checagem com pelo menos uma hora entre os rastreios. Os resultados obtidos neste trabalho estão abaixo das recomendações dadas por Higgins (1999) de que o RTK pode ser adequado para levantamentos com exigências de alguns centímetros, e para mais alta precisão, com até um centímetro deve ser restrito para linhas de base menores que $1 \mathrm{~km}$.

De modo geral os levantamentos RTK ficaram abaixo da precisão no nivelamento geométrico classe IIN e melhores que os nivelamentos GNSS estáticos. As discrepâncias entre os rastreios e processamentos, transformadas no indicador $\mathrm{a}_{\mathrm{gps}}$ variaram de 2 a $105 \mathrm{~mm}$ com média geral de 27,6 $\mathrm{mm}$.

\subsection{Geração do geóide}

A geração de um geoide neste trabalho teve dois objetivos: atender à recomendação padrão de usar a ondulação geoidal para a transformação das altitudes; e fornecer subsídios para as comparações com procedimentos de uso direto do nivelamento GNSS.

No procedimento comum adotado correntemente na prática de geração de geoide a partir de uma rede triangular (seção2.1.4) e de diferenças entre as altitudes ortométricas e elipsoidais, as ondulações podem ter erros não detectados. Ao ser usado este geoide para transformações de novos 
pontos GNSS, que por sua vez também podem conter erros grosseiros, o resultado final não terá precisão nem confiabilidade. Portanto os pontos com erros grosseiros dos levantamentos deste trabalho não seriam descobertos se fosse adotada essa metodologia simplificada e somente foi possível obter um geoide com boa precisão de $6 \mathrm{~mm}$ para a área da UFPE,devido à existência de repetições de seções de rastreio e uso de recursos computacionais de detecção de erros. Os processamentos do diversos levantamentos mostraram que obter um geoide de alta precisão exige procedimentos demorados e muito rigorosos, que não são compatíveis com as necessidades de rapidez em obras de engenharia.

\subsection{Sugestões}

Os erros dos nivelamentos GNSS ocorreram por vários motivos não identificados, mas como houve discrepâncias devido aos equipamentos e software usados para levantamentos e processamento, é necessário que existam procedimentos que garantam a qualidade do nivelamento, além de uma de verificação preliminar da compatibilidade da precisão do método adotado (estático longa duração, estático rápido, cinemático, TRK, etc.) é compatível com as exigências do projeto ou obra. Os procedimentos considerados adequados para controle dos erros de altitudes com base nos resultados desta pesquisa e respaldados pela literatura são elencados a seguir.

É necessário que cada ponto em métodos rápidos seja rastreado pelo menos duas vezes. 0 motivo principal é que os rastreios rápidos podem ser afetados por multicaminhamento (ICMS, 2014). A medição redundante com verificação de consistência é uma forma de controle dos erros de medições GNSS (Wolf \& Ghilani, 1997; Seeber, 2003), faz parte de recomendações de normas de GNSS como LINZ (2012) e é mais vantajoso que aumentar o tempo de rastreio (Svábensky \& Weigel, 2002).

As discrepâncias ocorridas pelo de uso de equipamentos diferentes e processamentos em diferentes softwares podem ser detectadas com a realização de medições em campos de testes, sobre um conjunto de pontos com coordenadas já conhecidas, com tempos de rastreio e linhas de base similares ao local de trabalho e medições abundantes. Este processo de calibração permitirá que sejam identificadas as diferenças entre equipamentos e softwares e analisados os motivos de discrepâncias significativas. Após eliminação dos erros grosseiros as médias e desvios padrões das discrepâncias podem ser avaliados com o indica- dor $\mathrm{a}_{\text {gps }}$ dado pela equação 2 e comparados com as precisões requeridas para a obra ou projeto. 0 uso de campos de testes com fins de checagem de equipamentos e softwares é descrito em Svábensky \& Weigel (2002), sugerido em Nabed et al. (2002) e inclusive fazia parte de normas mais antigas de levantamentos como GSD (1992).

Para os casos considerados mais críticos neste trabalho, alta precisão de altitude ortométricas necessária para canais de declividade muito baixa, foi mostrado que é possível uma análise dos sentidos de declividades da ondulação do geoide com as declividades de obras, que podem permitir o uso direto da altitude GNSS nos casos favoráveis (declividade em sentidos contrários, seção 2.1.6). Nos casos desfavoráveis e em outras obras que exijam alta precisão devem ser observados os procedimentos padrões e uso de um geoide com qualidade compatível, obtido com metodologia adequada, observações abundantes e ajustamento rigoroso, seguindo regras bem definidas como as detalhadas em Zilkoski et al. (1997).

Pode ser usado o nivelamento GNSS diretamente nos casos desfavoráveis (declividades de mesmo sentido) para obras de nível de precisão baixo e médio, mesmo em obras com extensão de até centenas de metros. Para isso é necessário que as discrepâncias do método de rastreio sejam avaliadas previamente em uma área de teste, e sejam calculadas as diferenças entre as declividades (declividade efetiva entre o gradiente do geóide e da obra) com base em um geoide global ou nacional que esteja disponível para consulta.

\section{Conclusões}

Os erros nos nivelamentos GNSS, que foram analisados neste trabalho e suas influências na geração de um geoide e na respectiva precisão da ondulação geoidal, visando as implicações em implantação de projetos de engenharia, em particular, na determinação das altitudes dos elementos de obras de drenagem, foram considerados os fatores mais críticos para o uso das altitudes GNSS diretamente.

No caso testado, geração de geoide na área da UFPE e seu entorno, as análises dos diversos levantamentos e processamentos executados e geração de mapas de ondulações geoidais permitem concluir que o nivelamento GNSS com rastreios de apenas $15 \mathrm{~min}$, ou menos, é um dos fatores que mais afeta a qualidade do mapageoidal, de tal modo que a precisão necessária pode ficar abaixo do exigido para certas obras de engenharia.

Quanto ao uso direto de altitude elipsoidal 
para obras de engenharia as conclusões com base nos dados deste trabalho são listadas a seguir

Devido à significativa ocorrência dessas altitudes com erros grosseiros recomenda-se a repetição de rastreios em todos os pontos. Para a identificação de discrepâncias por diferenças entre softwares e equipamentos, pode ser sugerida a execução de testes em rede geodésica com coordenadas muito bem conhecidas ou em campo de calibração.

É possível usar a altitude elipsoidal para exigências de baixa e média precisão, como em obras com declividades superiores a $0,5 \%$ ou em mapeamentos com diferenças de cotas superiores a alguns decímetros, aplicando levantamentos estáticos rápidos. Ao usar RTK a precisão pode ser significativamente melhor, mas é recomendável executar um teste de verificação a partir de rede de pontos nivelados pelo método geométrico e comparar com as altitudes obtidas por RKT com e sem correção de geoide global.

No geral é necessário conhecer o sentido de declividade da ondulação geoidal da área, a partir de algum modelo de ondulação nacional, como o MAPGEO do IBGE, ou outro local ou regional disponível. Para aplicações em obras com declividades, como canais ou tubulações de esgoto, podem ocorrer duas situações. No primeiro caso quando as declividades da obra e geoide têm sentidos contrários a situação é favorável ao uso direto da altitude GNSS, pois este caso a declividade efetiva é igual a soma das duas. No segundo caso quando as declividades são de mesmo sentido o uso direto é desfavorável, porém ainda depende da precisão exigida para a obra. No caso desfavorável, a declividade efetiva é igual à declividade da obra menos a declividade do geóide.

Para obras de alta precisão, como canais de baixa declividade da ordem de $10 \mathrm{~mm} / \mathrm{km}$ é necessário verificar se a situação é favorável ou não. No caso desfavorável é preciso avaliar a redução da vazão em relação à finalidade da obra. Em qualquer caso é preciso usar método de rastreios com durações mais longas e repetidos.

\section{Referências}

ABNT. Associação Brasileira de Normas Técnicas. 1994. NBR 13133: Execução de Levantamento Topográfico. Rio de Janeiro: Associação Brasileira de Normas Técnicas. 35 p.

Arana, J.M . 2003. Determinação da ondulação geoidal com uso do GPS/nivelamento. In: XXI CONGRESSO BRASILEIRO DE CARTOGRAFIA, 2003, Belo Horizonte. Anais... Rio de Janeiro: SBC. 1 CD-ROM.

Arana, J.M. 2004. O Uso do GPS na determinação de al- titudes ortométricas. In: CONGRESSO BRASILEIRO DE CADASTRO TÉCNICO MULTIFINALITÁRIO, 2004, Florianópolis. Anais... Florianópolis: UFSC. 1 CD-ROM

Cerqueira, J.A.C. \& Romão, V.M. 2010. Definição de uma superfície geoidal local através de posicionamento por GPS (modelagem para a determinação de altitudes ortométricas através do posicionamento por satélites e nivelamento geométrico). Revista Brasileira de Cartografia, (62) ed. esp: 307-315.

El-Shazly, A.H. 2005. GPS levelling without geoid in Egypt applied to Borg Al-Arab city. In: FIG WORKING WEEK 2005 AND GSDI-8, Cairo, 2005, Proceedings... International Federation of Surveyors (FIG) p. 1-12. Disponível em: <http://www.fig.net/pub/cairo/papers/ts_33/ts33_02_elshazly.pdf $>$. Acesso em 10 out 2012.

ENGEFOTO. Engefoto Engenharia e Aerolevantamentos. 2009. Prefeitura Municipal de Recife. Relatório Conclusivo. Curitiba: Engefoto, 400 p.

Goldani, D. \& Quintas, M.C.L. 2010. Um modelo geoidal para o estado do Paraná: aplicações da integral de Stokes e de um valor do geopotencial. Boletim de Ciências Geodésicas. 16(1). 104-124.

GSD. Geodetic Survey Division. 1992. Guidelines and specifications for GPS Surveys Release 2.1. Canada: Geodetic Survey Division, Canada Centre for Surveying, Surveys, Mapping and remote Sensing sector. Disponível em: <ftp://ftp.glonass-iac.ru/REPORTS/ OLD/NRCAN/GuidelinesSpecifications.pdf>. Acesso em 20 mai 2015.

Higgins, M.B. 1999. Heighting with GPS: Possibilities and Limitations. In: GEODESY AND SURVEYING IN THE FUTURE: THE IMPORTANCE OF HEIGHTS, JUBILEE SEMINAR: 25 YEAR OF MOTORISED LEVELLING, 1999. Gavle, Sweden. Proceedings...International Federation of Surveyors (FIG), p. 1-10. Disponível em: <http://www.fig.net/commission5/ reports/gavle/higgins.pdf>. Acesso em 20 out 2012 ICSM. Intergovernmental Committee on Surveying and Mapping. 2014. Guideline for Control Surveys by GNSS Special Publication 1. Version 2.1. Canberra, Austrália: ICSM, Permanent Committee on Geodesy (PCG). 21p. 2014. Disponível em: <http://www. icsm.gov.au/publications/sp1/Guideline-for-Control-Surveys-by-GNSS_v2.1.pdf>. Acesso em 07 mai 2015.

LINZ. Land Information New Zealand. 2012. Guidelines for Simplified Geodetic Control Survey. V2.1. New Zealand: National x Geodetic Office. 20 p. Disponível em: <http://www.linz.govt.nz/system/files_force/ media/pagesattachments/Guidelines $\% 20$ for $\% 20$ Order\%205\%20Control\%20Surveys\%20_Simplified_\%20v2.1.pdf?download=1>. Acesso em 07 mai 2015.

Monico, J.F.G. 2000. Posicionamento pelo NAVSTAR/GPS: Descrição, Fundamentos e Aplicações. São Paulo: Editora UNESP. 287 p.

Nabed, A.N., Gourine, B., Ghezali, B., Zeggai, A \& Taibi, H. 2002. Some GPS guidelines and recommendations for large-scale applications. In: FIG XXII INTERNA- 
TIONAL CONGRESS, 2002, Washington, D.C. USA. Proceedings... International Federation of Surveyors (FIG) p. 1-12. Disponível em: <https://www.fig.net/ resources/proceedings/fig_proceedings/fig_2002/ Ts5-6/TS5_6_nabed_etal.pdf>. Acesso em 07 mai 2015.

NOAA. National Oceanic and Atmospheric Administration. 2008. NOAA Technical Memorandum NOS NGS 59 Guidelines for Establishing GPS-Derived Ellipsoid Heights. Silver Spring, Maryland: National Geodetic Survey. 19 p. Disponível em: <http://www.ngs.noaa. gov/PUBS_LIB/NGS592008069FINAL2.pdf>. Acesso em 07 mai 2015.

Ollikainen, M. 1997. GPS levelling results from two test areas in Finland. In: F.K Brunner (Ed). Advances in Positioning and Reference Frames. IAG Scientific Assembly Rio de Janeiro 1997. Springer-Verlag. V. 118. p. 301-306.

Santos, M.A. 2009. Metodologia para obtenção de altitudes ortométricas através de interpolação de modelos geoidais locais definidos por GPS/nivelamento e gravimetria. Recife, 180p. Dissertação de Mestrado, Programa de Pós-Graduação em Ciências Geodésicas e Tecnologias da Geoinformação, CTG, Universidade Federal de Pernambuco.

Seeber, G. 2003. Satellite Geodesy: foundations, methods and applications. Berlin: Walter de Gruyter. 608 p.

Silva, C.V.A. 2012. Estudos das discrepâncias relativas entre as altitudes ortométricas e geométricas e suas implicações em trabalhos de Engenharia. Recife, 190p. Dissertação de mestrado, Programa de Pós-Graduação Ciências Geodésicas e Tecnologias da Geoinformação, CTG, Universidade Federal de Pernambuco.

Souza, D.V. 2006. Avaliação de distorções da rede altimétrica fundamental no Sul/Sudeste do Brasil usando o geóide e GPS. 124 p. Dissertação de Mestrado, Curso de pós-graduação em Geofísica, Instituto de Astronomia, Geofísica e Ciências Atmosféricas IAG/USP, São Paulo.

Souza, D.V \& Sá, N.C. 2007. Identificação de distorções em redes altimétricas usando geóide e GPS. Revista Brasileira de Cartografia. 59(3): 199-212.

Stepniak, K., Baryla, R., Wielgosz, P. \& Kurpinski, G. 2013. Optimal data processing strategy in precise GPS lev-

Manuscrito 590

Editores: Tatiana Silva da Silva e Paulo A. de Souza. elling Net. ActaGeodyn. Geomater. 10(4): 443-452.

Svábensky, O. \& Weigel,J. 2002. Accuracy management in GPS engineering applications. In: FIG INTERNATIONAL CONGRESS, XXII, 2002,Washington D.C. USA, Proceedings... International Federation of Surveyors (FIG), p. 1-11. Disponível em: <https://www. fig.net/resources/proceedings/fig_proceedings/ fig_2002/Js28/JS28_svabensky_weigel.pdf>. Acesso em 07 mai 2015.

Werlich, R.M.C., Krueger, C.P \& Huinca, S.C.M. 2012. Análise da altitude elipsoidal quando inseridos parâmetros próprios de calibração de antenas GPS em posicionamentos de alta precisão. In: SIMPÓSIO BRASILEIRO DE GEOMÁTICA, III, Anais... Presidente Prudente: UNESP. 1 CD ROM p. 223-227.

Willgalis, S., Seeber, G., Krueger, C. P \& Romão, V.M.C. 2003. A real time GPS reference network for cadastral surveys in Recife, Brazil. Revista Brasileira de Cartografia. 55(01): 1-10.

Wolf, P.R. \& Ghilani, C.D. 1997. Adjustment Computations statistic and least squares in Surveying and Gis. New York: John Wiley \& Sons. 564 p.

Zhang, K.F., Dodson, A.H. \& Chen, W. 2000. Factors affecting FFT gravimetric geoid determination precision. Pergamon, Physics and Chemistry of the Earth, 25(1): 31-37. Disponível em: <http://www.sciencedirect. com/science/article/pii/S1464189500000065>. Acesso em 07 mai 2015.

Zhan-Ji, Yang. 1998. Precise determination of local Geoid and its Geophysical Interpretation. Hong Kong, 144 p. Ph. D. thesis, Department of Land Surveying and Geo-informatics, The Hong Kong Polytechnic University. Disponível em <https://www.researchgate. net/publication/234459832_Precise_determination_of_local_geoid_and_its_geophysical_interpretation>. Acesso em 10 mai 2015.

Zilkoski, D., D’Onofrio, J. D. \& Frakes, S. 1997: Guidelines for Establishing GPS-Derived Ellipsoid Heights (Standards: $2 \mathrm{~cm}$ and $5 \mathrm{~cm}$ ), Version 4.3, NOAA Technical Memorandum NOS NGS-58. Silver Spring, MD: National Geodetic Survey Information Center. Disponível em: <http://www.ngs.noaa.gov/PUBS_LIB/ NGS-58.html>. Acesso em 07 mai 2015. 